\title{
CLINICAL SYMPTOMS AND CHEST X-RAY FINDINGS FOR EVALUATION OF CHEST X-RAY IN MANAGEMENT AND PREDICTION OF CLINICAL OUTCOME OF CONFIRM CASES OF COVID-19
}

\author{
Khawaja Muhammad Baqir Hassan, Tathir Baqir Hassan, Shakil Sarwar, Irfan Najam Sheen, Farrukh Islam, \\ Syed Aown Raza Shah Bokhari*, Muhammad Shahbaz Shoaib \\ Combined Military Hospital Malir/National University of Medical Sciences (NUMS) Pakistan, *Armed Forces Institute of \\ Cardiology/National Institute of Heart Disease (AFIC/NIHD)/National University of Medical Sciences (NUMS) \\ Rawalpindi Pakistan
}

\begin{abstract}
Objective: To study clinical symptoms and chest X-ray findings for evaluation of chest X-ray in management of confirmed cases of COVID-19 and predicting the clinical outcome.

Study Design: Cross sectional study.

Place and Duration of Study: The departments of Radiology \& Medicine of Combined Military Hospital Malir, from Mar to May 2020.

Methodology: The sample used in this study consists of 73 patients. All the standard frontal projections of chest X-ray of PCR confirmed COVID-19 patients were studied on computer and findings were noted

Results: At the aggregate, the study indicates that there is no Significant Connection in between the clinical symptoms, their severity and chest X-ray findings.

Conclusion: There is no significant connection found between the severity of clinical symptoms and chest $\mathrm{X}$-rays suggesting that chest X-Ray cannot be a reliable indicator to predict the clinical outcome of the patient and has limited role in management of patient. Clinical assessment is still the main stay of the patient management.
\end{abstract}

Keywords: COVID-19, Chest X-ray, Clinical symptoms, Rt-PCR.

This is an Open Access article distributed under the terms of the Creative Commons Attribution License (http://creativecommons.org/licenses/by/4.0), which permits unrestricted use, distribution, and reproduction in any medium, provided the original work is properly cited.

\section{INTRODUCTION}

Coronavirus disease 2019 (COVID-19) is viral pneumonia which has been recently encountered. It is caused by a jumped up virus which has been named severe acute respiratory syndrome coronavirus 2 (SARS-CoV-2) ${ }^{1,2}$. This infection was seen in Chinese population in December 20193,4, in the Wuhan province of China. This viral pneumonia is different from its precursors in term of its virulence and rapid spread 5 causing pandemic.

More than 4 million cases have been reported globally so far. More than 3500 deaths have also been related to COVID-19 in China ${ }^{6}$. In addition to this disease has rapidly spread in the whole world and caused $>3000$ deaths in world 7 . It has caused $>14,0000$ confirmed cases in USA

Correspondence: Dr Khawaja Muhammad Baqir Hassan, Dept of Radiology, CMH Malir, Karachi Pakistan

Received: 16 Jun 2020; revised received: 26 Aug 2020; accepted: 31 Aug 2020 and hundred thousand death related to it till writing of this article 8 . Europe has also become one of the epicenters for the pandemics affecting United Kingdom, Spain, Italy and France more in European continent ${ }^{8}$. Other countries of Europe have also been badly affected ${ }^{9}$.

\section{METHODOLOGY}

This cross sectional study was conducted in the department of Radiology of Combined Military Hospital, Malir. Non-probability consecutive sampling technique was used to collect the data. Sample size was $n=73$. Inclusion criteria was, confirmed COVID-19 by PCR of any age and gender, asymptomatic having positive contact history or having fever, dry cough, sore throat, diarrhea and $\mathrm{SOB}$ that require admission. The maximum period of stay in the hospital that was monitored is 21 days. Exclusion criteria was all the patients who were suspected of COVID-19 despite having high probability of COVID-19 and positive contact history but were negative on PCR. Patient 
who stayed for more than 21 days or are still under treatment were excluded from the study.

Study was carried out after informed consent from the patients. The chest X-ray of the patients was done on the advice of the medical specialist. The standard technique of chest X-ray (PA-view) was used for the patients in the dedicated x-ray room for stable patients. The unstable patients went under bedside portable radiology. The chest X-ray of the same patient was reported by two different radiologists. CR system by AGFA was used for this purpose. Inversion of the chest $X$-ray on console was also used to evaluate the findings. The clinical symptoms fever, dry cough, sore throat, SOB, and diarrhea were recorded day wise. Clinical symptomology and the chest X-ray findings were recorded on pre designed Performa. The chest X-ray was repeated on every 5th day of admission and the symptoms and signs were also recorded accordingly. The chest X-ray findings were categorized as normal, uni or bilateral pulmonary infiltrates uni or bilateral peripheral opacities, obscured uni or bilateral hemi diaphragms, ground glass opacities and mixed opacities where infiltrates and opacities both were present. The records were taken and chest X-rays were done on the specified days, i.e. on 1st day of admission, 5th, 10th and 15th post admission days. There was a definite clinical outcome in these patients as either discharged or dead. Chest X-ray done other than specified days was not included in the study.

The disease severity is classified as mild, moderate and severe on the basis of the clinical symptoms and percentage involvement of the lungs by the opacities on the chest X-ray. In our study if area involvement is $>50 \%$ than it is classified as severe disease that requires oxygen supplementation and may proceed to intubation.

Data was analyzed with statistical analysis program (SPSS version 22). Frequency and percentage was computed. The clinical symptoms and chest X-ray findings were computed. Their frequencies and percentages were calculated. The means were individually calculated for age.

\section{RESULTS}

Total 73 patients were followed as they were available at the point of study, out of which $64(87.7 \%)$ were male and $9(12.5 \%)$ were females. Their mean age was $36.19 \pm 14.018$ years. The minimum age was 19 years and maximum age was 69 years.

There were 17 patients who were asymptomatic but had positive contact history. They remained asymptomatic throughout the duration of the admission and their chest X-rays also remained normal.

Table-I: Clinical symptoms and chest $X$-ray findings on Day 1.

\begin{tabular}{|c|c|}
\hline & n (\%) \\
\hline \multicolumn{2}{|l|}{ Clinical Symptoms } \\
\hline Fever & $20(27.4)$ \\
\hline Dry Cough & $5(6.8)$ \\
\hline Sore throat & $1(1.4)$ \\
\hline Fever, Dry Cough & $8(11.0)$ \\
\hline Fever, Dry Cough, SOB & $5(6.8)$ \\
\hline Fever, Dry Cough, SOB, Sore throat & $3(4.1)$ \\
\hline Dry Cough, Sore Throat & $2(2.7)$ \\
\hline Positive Contact & $17(23.3)$ \\
\hline SOB, Dry Cough & $2(2.7)$ \\
\hline Fever, Sore throat & $4(5.5)$ \\
\hline Fever, Sore throat, Dry Cough & $3(4.1)$ \\
\hline Fever, SOB & $1(1.4)$ \\
\hline Fever, Dry Cough, Diarrhea & $2(2.7)$ \\
\hline Total & $73(100.0)$ \\
\hline \multicolumn{2}{|l|}{ Chest X-ray Findings } \\
\hline Normal & $51(69.9)$ \\
\hline Right Peripheral Opacities & $2(2.7)$ \\
\hline Left Peripheral Opacities & $1(1.4)$ \\
\hline Bilateral Peripheral Opacities & $2(2.7)$ \\
\hline Left Pulmonary Infiltrates & $1(1.4)$ \\
\hline Bilateral Pulmonary Infiltrates & $6(8.2)$ \\
\hline Ground Glass Opacities Scatters & $2(2.7)$ \\
\hline $\begin{array}{l}\text { Mixed Opacities and Pulmonary } \\
\text { Infiltrates }\end{array}$ & $8(11.0)$ \\
\hline Total & $73(100.0)$ \\
\hline
\end{tabular}

Table-I shows the frequency of the clinical symptoms of the patients on the 1st day of the admission.

Table-II shows the frequencies of the clinical symptoms and chest X-ray findings on the day 1 . All those symptoms that had normal chest $X$-rays 
were excluded from this table to keep the things simple.
Table-III shows combined frequencies of the clinical symptoms and chest $\mathrm{X}$-ray findings

Table-II: The frequencies of Chest X-ray findings and clinical symptoms on day 1.

\begin{tabular}{|c|c|c|c|c|c|c|c|c|c|}
\hline \multirow{3}{*}{ Chest X-ray Findings Day 1} & \multicolumn{9}{|c|}{ Clinical Symptoms on Day 1} \\
\hline & Fever & $\begin{array}{c}\text { Dry } \\
\text { Cough }\end{array}$ & $\begin{array}{c}\text { Fever, Dry } \\
\text { Cough }\end{array}$ & $\begin{array}{c}\text { Fever, Dry } \\
\text { Cough, } \\
\text { SOB }\end{array}$ & $\begin{array}{l}\text { Fever, Dry } \\
\text { Cough, SOB, } \\
\text { Sore Throat }\end{array}$ & $\begin{array}{c}\text { SOB, Dry } \\
\text { Cough }\end{array}$ & $\begin{array}{c}\text { Fever, } \\
\text { SOB }\end{array}$ & \begin{tabular}{|c|} 
Fever, Dry \\
Cough, \\
Diarrhea
\end{tabular} & Total \\
\hline & n (\%) & n (\%) & n (\%) & n ( $\%)$ & n (\%) & n (\%) & n (\%) & n (\%) & n (\%) \\
\hline Right Peripheral Opacities & $1(2.2)$ & $1(2.2)$ & - & - & - & - & - & - & $2(4.3)$ \\
\hline Left Peripheral Opacities & $1(2.2)$ & - & - & - & - & - & - & - & $1(2.2)$ \\
\hline Bilateral Peripheral Opacities & $1(2.2)$ & - & - & $1(2.2)$ & - & - & - & - & $2(4.3)$ \\
\hline Right Pulmonary Infiltrates & - & - & - & - & - & - & - & - & - \\
\hline Left Pulmonary Infiltrates & - & - & $1(2.2)$ & - & - & - & - & - & $1(2.2)$ \\
\hline Bilateral Pulmonary Infiltrates & $3(6.5)$ & - & $1(2.2)$ & $1(2.2)$ & $1(2.2)$ & - & - & - & $6(13)$ \\
\hline Ground Glass Opacities & - & - & $1(2.2)$ & - & & $1(2.2)$ & - & - & $2(4.3)$ \\
\hline $\begin{array}{l}\text { Scattered Mixed opacities and } \\
\text { pulmonary infiltrates }\end{array}$ & $2(4.3)$ & - & - & $2(4.3)$ & $2(4.3)$ & - & $1(2.2)$ & $1(2.2)$ & $8(17.4)$ \\
\hline Normal & $12(26.1)$ & $4(8.7)$ & $5(1.9)$ & $1(2.2)$ & - & $1(2.2)$ & - & $1(2.2)$ & $24(52.2)$ \\
\hline Total & $20(43.5)$ & $5(10.9)$ & $8(17.4)$ & $5(10.9)$ & $3(6.5)$ & $2(4.3)$ & $1(2.2)$ & $2(4.3)$ & $46(100)$ \\
\hline
\end{tabular}

Table-III: Clinical symptoms and chest X-ray findings frequencies Day 5.

\begin{tabular}{l|c}
\hline Clinical Symptoms Day 5 & $\mathbf{n ~ ( \% )}$ \\
\hline Clinical Symptoms & $5(6.8)$ \\
\hline Asymptomatic & $15(20.5)$ \\
\hline Fever & $6(8.2)$ \\
\hline Dry Cough & $1(1.4)$ \\
\hline Sore throat & $7(9.6)$ \\
\hline Fever, Dry Cough & $4(5.5)$ \\
\hline Fever, Dry Cough, SOB & $2(2.7)$ \\
\hline Fever, Dry Cough, SOB, Sore throat & $3(4.1)$ \\
\hline Dry Cough, Sore Throat & $17(23.3)$ \\
\hline Positive Contact & $2(2.7)$ \\
\hline SOB, Dry Cough & $4(5.5)$ \\
\hline Fever, Sore throat & $4(5.5)$ \\
\hline Fever, Sore throat, Dry Cough & $1(1.4)$ \\
\hline Fever, SOB & $1(1.4)$ \\
\hline Fever, Dry Cough, Diarrhea & $1(1.4)$ \\
\hline Missing due to death & $73(100.0)$ \\
\hline Total & $\mathbf{n ~ ( \% )}$ \\
\hline Chest X-ray Findings Day 5 & $51(69.9)$ \\
\hline Findings & $2(2.7)$ \\
\hline Normal & $1(1.4)$ \\
\hline Right Peripheral Opacities & $1(1.4)$ \\
\hline Left Peripheral Opacities & $1(1.4)$ \\
\hline Bilateral Peripheral Opacities & $2(2.7)$ \\
\hline Left Pulmonary Infiltrates & $6(8.2)$ \\
\hline Bilateral Pulmonary Infiltrates & $1(1.4)$ \\
\hline Ground Glass Opacities Scatters & $(100.0)$ \\
\hline Mixed opacities and pulmonary infiltrates & \\
\hline Missing due to death & \\
\hline Total & \\
\hline
\end{tabular}

on day 5 of admission.

Table-IV shows frequencies of clinical symptoms and chest X-ray findings on 5th day of admission.

The table- $\mathrm{V}$ shows the frequency of the clinical symptoms and the chest $\mathrm{X}$-ray findings on day 10.

\section{DISCUSSION}

COVID-19 has become a pandemic. Six commonly presented clinical symptoms of the disease have been described ${ }^{10-12}$. Most common are fever, dry cough, Sore throat, shortness of breath, anosmia and dysgeusia ${ }^{12}$. Out of these six fevers and dry cough are the commonest ${ }^{12}$. Atypical symptoms like diarrhea, gastritis, ear ache and skin manifestations have also been noted in COVID1913. The clinical diagnosis mainly depends upon good detailed history ${ }^{11,14}$ especially the contact and travel ${ }^{15,16}$.

No definitive treatment or vaccine has been developed for COVID-1916. The gold standard for confirmation of COVID-19 is rt-PCR ${ }^{17}$. No other reliable lab indicator that can specifically monitor the clinical course and progress of COVID-19 disease is present. COVID-19 can cause multi organ failure or complications related to the organ involved $10,18,19$. The severity of the disease has been more markedly observed in patients 
with co-morbids like ischemic heart disease, Diabetes mellitus ${ }^{20}$ and respiratory diseases such as COPD, Asthma and pulmonary tuberculosis. sensitive in diagnosis of COVID-19 where PCR is negative ${ }^{22}$. Although few centers have described the role of chest X-Ray in triage and screening of

Table-IV: Frequencies of clinical symptoms and chest X-ray findings on day 5 .

\begin{tabular}{|c|c|c|c|c|c|c|c|c|c|c|c|}
\hline \multirow{3}{*}{ Chest X-ray Findings } & \multicolumn{11}{|c|}{ Clinical Symptoms } \\
\hline & 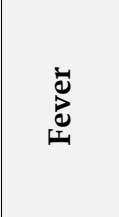 & $\begin{array}{l}\frac{\pi}{60} \\
0 \\
0 \\
0 \\
0\end{array}$ & 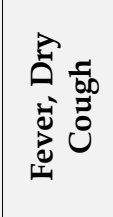 & 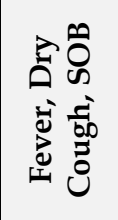 & 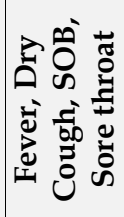 & 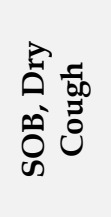 & 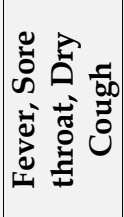 & $\begin{array}{l}\infty \\
0 \\
\omega \\
01 \\
01\end{array}$ & 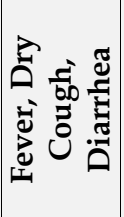 & 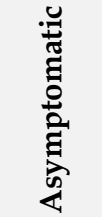 & సี \\
\hline & n (\%) & n (\%) & n (\%) & n (\%) & n (\%) & n (\%) & n ( $\%)$ & n (\%) & n (\%) & n (\%) & n ( $\%)$ \\
\hline Right Peripheral Opacities & - & $1(4.5)$ & - & - & - & - & - & - & - & $1(4.5)$ & $2(9.1)$ \\
\hline Left Peripheral Opacities & $1(4.5)$ & - & - & - & - & - & - & - & - & - & $1(4.5)$ \\
\hline Bilateral Peripheral Opacities & $1(4.5)$ & - & - & - & - & - & - & - & - & - & $1(4.5)$ \\
\hline Right Pulmonary Infiltrates & - & - & - & - & - & - & - & - & - & - & - \\
\hline Left Pulmonary Infiltrates & - & - & $1(4.5)$ & - & - & - & - & - & - & - & $1(4.5)$ \\
\hline Bilateral Pulmonary Infiltrates & $3(13.6)$ & - & $1(4.5)$ & $2(9.1)$ & - & - & $1(4.5)$ & - & - & $1(4.5)$ & $8(36.4)$ \\
\hline Ground Glass Opacities & - & - & $1(4.5)$ & - & - & $1(4.5)$ & - & - & - & - & $2(9.1)$ \\
\hline $\begin{array}{l}\text { Scatters Mixed Opacities and } \\
\text { Pulmonary Infiltrates }\end{array}$ & $1(4.5)$ & - & - & $2(9.1)$ & $1(4.5)$ & - & - & $1(4.5)$ & $1(4.5)$ & - & $6(27.3)$ \\
\hline Total & $6(27.3)$ & $1(4.5)$ & $3(13.6)$ & $4(18.2)$ & $1(4.5)$ & $1(4.5)$ & $1(4.5)$ & $1(4.5)$ & $1(4.5)$ & $2(9.1)$ & $21(100)$ \\
\hline
\end{tabular}

The severity of disease has been directly linked to advancement in the age as well12,21.

Respiratory symptoms are the commonest symptoms. Although chest X-ray has been used

Table-V: Frequency of chest X-ray findings and clinical symptoms on Day 10.

\begin{tabular}{|c|c|}
\hline & n (\%) \\
\hline \multicolumn{2}{|l|}{ Clinical Symptoms } \\
\hline Asymptomatic & $41(56.2)$ \\
\hline Fever & $4(5.5)$ \\
\hline Dry Cough & $4(5.5)$ \\
\hline Fever, Dry Cough & $3(4.1)$ \\
\hline Positive Contact & $17(23.3)$ \\
\hline Fever, Sore throat & $1(1.4)$ \\
\hline Total & $70(95.9)$ \\
\hline Missing & $3(4.1)$ \\
\hline Total & $73(100.0)$ \\
\hline \multicolumn{2}{|l|}{ Chest X-ray Findings } \\
\hline Normal & $67(91.8)$ \\
\hline Right Pulmonary Infiltrates & $1(1.4)$ \\
\hline Bilateral Pulmonary Infiltrates & $2(2.7)$ \\
\hline Total & $70(95.9)$ \\
\hline Missing & $3(4.1)$ \\
\hline Total & $73(100.0)$ \\
\hline
\end{tabular}

for screening and diagnosis 22 . CT is used in triage and screening for COVID-19 patients22. In one study the HRCT chest has proven to be more suspected corona cases ${ }^{23}$ HRCT chest is better. HRCT chest is expensive, having high radiation exposure and cannot be used on daily basis to monitor the disease progress ${ }^{24}$. Chest $\mathrm{X}$-ray is easily available, less hazardous and economical when compared to HRCT chest. Therefore chest X-ray remains the most commonly employed radiological modality.

Four important changes on chest X-ray have been described 4 . Although they are not specific for COVID-19 but in rt-PCR confirmed patients, these findings can be reliably be attributed to COVID-1925. These are peripheral opacities, basal consolidations, pulmonary infiltrates and silhouetting of hemi diaphragms. These findings can be uni lateral or bilateral, single or multiple in COVID-19 patients.

Studies have shown that respiratory symptoms are the most common manifestations of the majority of the patients ${ }^{4,10}$. Signifying importance of chest radiology. However no study has been shown where chest $\mathrm{X}$-ray is also being used as monitoring tool. Chest X-ray like HRCT has no role in the diagnosis or screening of COVID-19 even where clinical history and examination are highly suggestive ${ }^{25}$. 
Chest X-ray however is being used to monitor the COVID-19 pneumonia. Few studies have described the role of chest X-ray in response evaluation and early detection of complications. Although the HRCT chest still more sensitive and specific.

In this study the data analysis shows that fever was the main clinical symptom seen in confirmed COVID-19 patients (table-I). Similarly the most common chest X-ray finding was mixed opacities followed by pulmonary infiltrates (table-I). Only 21 patients out of 73 had positive chest $X$-rays. Therefore the frequencies between theses 21 positive chest $X$-rays and clinical symptoms of these patients was studied (table-II \& V). The analysis of tables-II \& IV for the estimation of frequencies of clinical symptoms and chest X-ray findings show that fever is the commonest symptom having maximum number of positive chest $X$-rays. The one missing value shown in the tableIV is due to the death of one patient. Rests of the clinical symptoms do not show significant change in their frequencies. On 5th day of admission patients with positive chest X-ray findings were still 21 (table-III). It is the same number of the patients as on day 1 except that one of the patients died. But a change of pattern was noted from mixed to bilateral pulmonary infiltrates. On day 1 the predominant chest $X$-ray finding was mixed pattern whereas on $5^{\text {th }}$ day it was bilateral pulmonary infiltrates. Rests of the chest X-ray findings were not significantly changed. It was also observed that 5 patients who were asymptomatic on the 5th day also had positive chest X-ray findings. This is another important point to be considered as being asymptomatic doesn't mean that silent chest $X$-ray changes can't occur.

It is clearly observed in table- $V$ that a significant number of the patients have become asymptomatic and more than $90 \%$ of chest X-rays are normal on $10^{\text {th }}$ day of admission. Two more patients who had severe disease died. On the day 14th of the admission all alive 70 patients became asymptomatic and their chest X-rays were normal, however they were discharged according to the protocol.
These treatments were given on various guidelines as no definite treatment plan is still available. Total of 73 patients were followed till their discharge or they died. The patients were analyzed on the basis of clinical symptoms and findings on chest X-ray. Four major chest X-ray findings are being attributed to COVID-19 in other studies were also confirmed in this study. Out of these the main chest X-ray findings were mixed pattern and bilateral pulmonary infiltrates. No such study has been found in literature especially in this region where the clinical symptoms were studied in along with chest X-ray findings. It was also found that all respiratory symptoms when combined with fever are likely to have some positive finding on chest $\mathrm{X}$-ray.

It is evident from the comparison of the clinical symptoms and chest $\mathrm{X}$-ray findings that chest X-ray has limited role in patient management. Although it can be used to classify the disease severity. But in our study the physicians had more emphasis on their clinical judgment and $\mathrm{O}_{2}$ saturation ${ }^{19}$.

\section{CONCLUSION}

The severity of the clinical symptoms and disease progression are not very well correlated with the chest X-ray findings. The chest X-ray has limited role in disease classification and management and has no role in predicting the clinical outcome. Chest X-Ray findings always follows the clinical course. Chest $X$-ray is not necessarily to be positive in isolated upper or lower respiratory systems, however if combined with symptoms like fever likelihood of positive chest X-ray findings is increased. Additionally it is not necessary that asymptomatic patients will have normal chest $X$-ray.

\section{CONFLICT OF INTEREST}

This study has no conflict of interest to be declared by any author.

\section{REFERENCES}

1. Shereen MA, Khan S, Kazmi A, Bashir N, Siddique R. COVID-19 infection: Origin, transmission, and characteristics of human coronaviruses. J Adv Res 2020; 24(1): 91-98.

2. Ghinai I, McPherson TD, Hunter JC, Kirking HL, Christiansen $\mathrm{D}$, Joshi $\mathrm{K}$, et al. First known person to person transmission of 
severe acute respiratory syndrome coronavirus 2 (SARS-CoV-2) in the USA. Lancet 2020; 395(1): 1137-44.

3. The epidemiological characteristics of an outbreak of 2019 novel coronavirus diseases (COVID-19) in China. Zhonghua Liu Xing Bing Xue Za Zhi 2020; 41(2): 145-51.

4. Kim ES, Chin BS, Kang CK, Kim NJ, Kang YM, Choi JP, et al. Clinical course and outcomes of patients with severe acute respiratory syndrome coronavirus 2 infection: A preliminary report of the first 28 patients from the korean cohort study on COVID-19. J Korean Med Sci 2020; 35(13): e142.

5. Wu JT, Leung K, Bushman M, Kishore N, Niehus R, de Salazar PM. Estimating clinical severity of COVID-19 from the transmission dynamics in Wuhan, China. Nat Med 2020; 26(4): 1-5.

6. Hanley B, Lucas SB, Youd E, Swift B, Osborn M. Autopsy in suspected COVID-19 cases. J Clin Pathol 2020; 73(5): 239-42.

7. Cron RQ, Chatham WW. The Rheumatologist's Role in COVID19. J Rheumatol 2020; 47(5): 639-42.

8. Pike WT, Saini V. An international comparison of the second derivative of COVID-19 deaths after implementation of social distancing measures. medRxiv 2020; 1(1): 1-7.

9. European Center for Disease Prevention and Control. Coronavirus disease 2019 (COVID-19) pandemic: increased transmission in the EU/EEA and the UK - seventh update. Eur Cent Dis Prev Control 2020; [Internet]. Availble from: https://www. ecdc.europa.eu/en

10. Singhal T. A Review of Coronavirus Disease-2019 (COVID-19). Ind J Pediat 2020; 87(1): 281-86.

11. Qin C, Zhou L, Hu Z, Zhang S, Yang S, Tao Y, et al. Dysregulation of immune response in patients with COVID-19 in Wuhan, China. Clin Infect Dis 2020; 71(15): 762-68.

12. Tian S, Hu N, Lou J, Chen K, Kang X, Xiang Z. Characte-ristics of COVID-19 infection in Beijing. J Infect 2020; 80(4): 401-06.

13. Cheung KS, Hung IF, Chan PP, Lung KC. Gastrointestinal Manifestations of SARS-CoV-2 Infection and Virus Load in Fecal Samples from the Hong Kong Cohort and Systematic Review and Meta-analysis. Gastroenterol 2020; 159(1): 81-95.

14. Wang Y, Wang Y, Chen Y, Qin Q. Unique epidemiological and clinical features of the emerging 2019 novel coronavirus pneumonia (COVID-19) implicate special control measures. J Med Virol 2020; 568-76.

15. Hsih WH, Cheng MY, Ho MW, Chou CH, Lin PC, Chi CY, et al. Featuring COVID-19 cases via screening symptomatic patients with epidemiologic link during flu season in a medical center of central Taiwan. J Microbiol Immunol Infect 2020; 53(3): 459-66.

16. Wu YC, Chen CS, Chan YJ. The outbreak of COVID-19: An overview. J Chin Med Assoc 2020; 83(3): 217-20.

17. Ai T, Yang Z, Hou H, Zhan C, Chen C, Lv W, et al. Correlation of chest CT and RT-PCR testing in coronavirus disease 2019 (COVID-19) in China: a report of 1014 Cases. Radiol 2020; 296(2): e32-40.

18. Wang S, Guo L, Chen L, Liu W, Cao Y, Zhang J, et al. A case report of neonatal COVID-19 infection in China. Clin Infect Dis 2020; 71(15): 853-57.

19. Inciardi RM, Lupi L, Zaccone G, Italia L, Raffo M, Tomasoni D, et al. Cardiac involvement in a patient with coronavirus disease 2019 (COVID-19). J Am Med Assoc Cardiol 2020; 5(7): 819-24.

20. Li B, Yang J, Zhao F, Zhi L, Wang X, Liu L, et al. Prevalence and impact of cardiovascular metabolic diseases on COVID-19 in China. Clin Res Cardiol 2020; 109(5): 531-38.

21. Dong XC, Li JM, Bai JY, Liu ZQ, Zhou PH, Gao L, et al. Epidemiological characteristics of confirmed COVID-19 cases in Tianjin. Zhonghua Liu Xing Bing Xue Za Zhi 2020; 41(5): 638-41.

22. Bai HX, Hsieh B, Xiong Z, Halsey K, Choi JW, Tran TML, et al. Performance of radiologists in differentiating COVID-19 from viral pneumonia on chest CT. Radiology 2020; 296(2): e46-54.

23. Kooraki S, Hosseiny M, Myers L, Gholamrezanezhad A. Coronavirus (COVID-19) Outbreak: What the department of radiology should know. J Am Coll Radiol 2020; 17(4): 447-51.

24. Jacobi A, Chung M, Bernheim A, Eber C. Portable chest X-ray in coronavirus disease-19 (COVID-19): A pictorial review. Clin Imag 2020; 64(1): 35-42.

25. Tapé C, Byrd KM, Aung S, Lonks JR, Flanigan TP, Rybak NR. COVID-19 in a Patient Presenting with Syncope and a Normal Chest X-ray. R I Med J 2013; 103(3): 50-51. 